\title{
Psychometric Properties of Self-Regulating Climate Questionnaire
}

\author{
Iranian Evolutionary and Educational \\ Psychology Journal \\ June 2020: 120-130 \\ (C) University of Hormozgan Publication 2020 \\ DOI: 10.29252/ieepj.2.2.120 \\ http://ieepj.hormozgan.ac.ir
}

\section{Roohollah Saranjam*}

\begin{abstract}
The study sought to determine the psychometric properties of self -regulatory climate questionnaire among Iranian students as well as comparing the self- regulatory climate in Gifted and Public Schools. The statistical population included the firstyear high school male students in gifted and public schools in 2018. In the first study, 200 students were selected through random sampling. 30 students were randomly assigned to each group via a random sampling method in the second study. The self-regulatory climate questionnaire was used for the collection of data. The reliability of the questionnaire was also evaluated by Cronbach's alpha and to test its validity, the confirmatory factor analysis was used. Also, the multivariate analysis of variance was used to test the research hypothesis. The findings showed that self-regulatory climate questionnaire had proper internal consistency for subscales and total scale. Besides, the fitness indices obtained from confirmatory factor analysis revealed that the scale had proper construct validity and all items had an appropriate load factor. The results also revealed that the gifted schools have a higher self-regulation climate. In general, the results of the present study supported the usefulness of the self-regulatory climate questionnaire among the Iranian sample and provided some evidence of the role of characteristics of the gifted schools in the self-regulatory climate. In general, self-regulatory climate is a valid and effective construct which has positive consequences for academic performance.
\end{abstract}

Keywords: self-regulatory climate, validity, reliability, gifted schools

\section{Introduction}

Learning is at the heart of the school and both teachers and students focus on it. The study of cognitive and motivational variables related to learning has been the subject of many studies (Paloş, Munteanu, Costea, \& Macsinga, 2011). One of the structures that affect learning is self-regulation. Studying the relationship between self-regulation and academic achievement has been one of the important aims in previous studies (Connor et al., 2010; McClelland \& Cameron, 2011).

Self-regulation is defined as the ability to regulate thinking, behavior, and emotions, and is a kind of control mechanism that enables a person to manage his attention, emotion, behavior, and cognition to engage in purposed activities such as learning (Connor et al., 2016). Zimmerman (2002) considers self-regulation as a process in which learners transform their mental capabilities into functional skills in the academic field. Self-regulated students regulate their goals and then select appropriate strategies related to them. These stu-

1. Hormozgan University of Medical Sciences, BandarAbbas, Iran

*Corresponding author email: rsaranjam@yahoo.com 
dents monitor themselves during the learning process, and their motivation increases with learning progress. Whereas the presented definitions mainly emphasize on individual and internal nature of self-regulation, the recent studies reflected a different view of self-regulation as self-regulatory climate. This construct is rooted in school climate research. Healthy climate can promote the affective outputs such as psychological health (McNeely, Nonnemaker, \& Blum, 2002) and cognitive ones like the achievement outcomes (Cohen, McCabe, Michelli, \& Pickeral, 2009). According to Ryan and Deci (2016), Self-regulatory climate is not an internal state of students or the combination of individual self-regulated behavior of students. The emphasis on self, referred mainly to the inherent motivation and capability of students to learn and grow. Hence, the self-regulatory climate reflects the external social environment promotes or declines innate psychological needs. The emphasis placed on climate indicates the normative state of schools. Students work below their potential when the school environment suppresses psychological needs; on the contrary, they operate at higher levels when a healthy and supportive climate strengthens psychological needs (Niemiec \& Ryan, 2009).

Therefore, the self-regulatory climate is an external motivational construct that a school can have or not. Of course, one of the reasons for the emphasis on the "Self" in self-regulation climate of a school is students' perception about it and its components. Adams, Ware, Miskell, and Forsyth (2016) consider self-regulatory climate as school norms which consisted of collective faculty trust in students, collective student trust in teachers, and student-perceived academic emphasis. Relation of this construct to the psychological needs of students presented by Deci and Ryan (2008) is evident. So that the collective faculty trust in students related to the need for autonomy support, collective student trust in teachers is consistent with the need for relational support, and the student-perceived academic emphasis is related to competence support. Collective faculty trust in students is more likely to be formed in schools where students are actively involved in their homework and show interest in learning. Collective student trust in faculty is also created at a school when teachers have a genuine commitment and belief in academic excellence and achievement from students view.

There is also an academic emphasis when students perceive school and teachers' emphasis on academic achievement and consider it as a learning opportunity (Adams et al., 2016).

A lot of research evidence has supported of the role of self-regulation in academic achievement and has been referred to it as a critical factor in learning (Connor et al., 2016; Wibrowski, Matthews, \& Kitsantas, 2017; Zee \& de Bree, 2017).

An important challenge in the area of self-regulation is the measurement of this structure. Several questionnaires have been developed to measure the self-regulation. The Motivated Strategies for Learning Questionnaire is one of these questionnaires, which is composed of two main sections of learning and motivation strategies. The questionnaire measures self-regulation with the items in the learning strategies section (Pintrich, Smith, Garcia, \& McKeachie, 1993). Another questionnaire used to measure self-regulation is the Learning and Study Strategies Inventory, which assesses skill, will, and self-regulation strategies (Weinstein, Palmer, \& Schulte, 1987). Self-Regulated Learning Interview Scale is another tool that as a structured interview, measures self-regulation learning strategies (Zimmerman \& Pons, 1986). In line with these studies, some efforts have been made to measure self-regulatory learning with more recent methods, such as the use of an elaborate think-aloud method (Azevedo \& Cromley, 2004).

Most of the efforts to measure self-regulation focused on assessing individual self-regulation strategies of learners. Efforts to measure individual self-regulation have measured this attribute as an intrinsic motivational 
feature based on definitions of it. Studies have suggested that self-regulation, although considered an intrinsic motivational construct, is also influenced by external factors such as the environment and interactions with others that have been studied as co-regulation (McCaslin, 2009). Hence, Self-regulation seems to be based more on external factors that influence it.

Self-regulation climate is based on self-determination theory. Self-determination theory explains the intrinsic motivation of individuals in pursuing their goals and their efforts to increase their potential (Deci \& Ryan, 2008). The self-regulatory climate emphasizes the effect of the school social environment on the student self-regulation. Niemiec and Ryan (2009) argue that when the social environment of people ignores their psychological needs, they tend to work below their capacity, and when their social environment satisfies their psychological needs, they increase their functions.

In accordance to Adams et al. (2016), we define the self-regulation learning climate as a set of normative conditions based on teacher-student interactions which can address the psychological needs of students, including autonomy, relatedness, and competence. It has been proven that the formation of a self-regulation learning climate in students is related to the environmental conditions of a school (Adams et al., 2016).

Some studies have indicated the difference in self-regulation between gifted and public students, and have shown that high-intelligence students have a higher self-regulation capacity (Greene, Moos, Azevedo, \& Winters, 2008; Ruban \& Reis, 2006). But according to our search, there is no comparison between gifted and public schools in the context of self-regulation climate.

Gifted schools in Iran are schools with facilities, levels of education, and attendance hours in school are higher than public schools. Gifted students must take a difficult placement test to accept for studying in these schools. In addition to the selection of students, teachers and school staff are also selected. Teachers with high teaching experience usually work in these schools, and the educational facilities, teaching methods, assignments and curriculum of these schools are different from public school. Gifted schools usually use a variety of teaching methods, such as slides, conferences by students, use of videos, school seminars, and so on. Other features of gifted schools include group activities and student participation in-class activities. In these schools, more than public schools, the emphasis is on group work and learning (Sajjadimonazah $\&$ pirkhaefi, 2017).

The self-regulation learning climate mainly reflects the social environment governing the learning environment and the teacher-student interaction at schools. The need for an appropriate tool for carrying out research related to self-regulation climate, lack of a self-regulatory climate questionnaire in Persian language and the necessity of validation this scale in accordance to Iranian culture were our incentives for doing this research. This scale benefited from good psychometric properties in the original study. Adams et al. (2016) have assessed the validity of the questionnaire by the exploratory factor analysis method at a very satisfactory level. Also, they have reported alpha of 0.97 for faculty trust in students, alpha of 0.92 for student trust in teachers and alpha of 0.83 for academic emphasis.

In the first study, we have investigated the psychometric properties of the self-regulatory climate questionnaire and in the second study, we have examined the differences in the self-regulatory climate between public and gifted schools. Therefore, we hypothesize that self-regulatory climate questionnaire benefits from good psychometric properties in Iranian sample and there is a significant difference in the self-regulatory climate between public and gifted schools. 


\section{Material and Method}

Participants: The present study was performed into two sections. In the first section, I have assessed the psychometric properties of the self-regulated questionnaire. To this aim, 200 male high school students were selected via random sampling. In the second section and to compare gifted and public schools in self-regulated climate, we have selected 30 students from each one of gifted and public schools via random sampling.

Procedure: The population of the study was male students studying in the schools of a city in Iran. Participants were recruited by random sampling method, and they completed a self-reported questionnaire. The participants were informed about the nature of the study, that participation was voluntary and anonymous, that they could withdraw from the study at any time, and that they were not obliged to respond to all questionnaire items. Also, the research plan was approved by the Ethics Committee of the university. Confirmatory factor analysis was performed to confirm the structure of self-regulatory climate questionnaire. Also, the MANOVA test was used to compare gifted and public schools in self-regulated climate and its components.

Methods: Participants were asked to complete the Adams, Forsyth, Dollarhide, Miskell, and Ware (2015) self-regulated climate Scale. This scale consisted of 15 questions and 3 subscales. The scale had a 5-point Likert-type response set ranging from 1 (strongly disagree) to 5 (strongly agree). Higher total scores indicate more self-regulated climate. Psychometric characteristics of this scale are well-documented in the original study (Adams et al., 2015). Adams et al. (2015) showed that structural equation modeling supports the theory that collective faculty trust in students, collective student trust in teachers, and student-perceived academic emphasis combine to form a self-regulatory climate. Also, they reported high Cronbach's alpha for Faculty trust in students, Student trust in teachers and Student-perceived academic emphasis $(0.97,0.91$ and 0.83 respectively).

In the current study, following a back-translation method, all items were translated into Persian by an English translator. Then, another translator translated all items back into English. Finally, the authors confirmed the final version of the questionnaire. The reliability of the full scale and subscales was evaluated by Cronbach's Alpha coefficient, and the validity of it was examined by confirmatory factor analysis. The analysis was performed using the SPSS software version 16, and the AMOS software version 16.

\section{Results}

The result is presented in four sections. In the first section, before the analysis, I checked the normality of data by the Kolmogorov-Smirnov test, and its result confirmed normality of data. In the second section, I present the correlation matrix and descriptive statistics (mean and standard deviation) of the factors of the self-regulated climate questionnaire, namely collective faculty trust in students, collective student trust in teachers, and student-perceived academic emphasis in Table 1.

In the third section, a confirmatory factor analysis, along maximum likelihood estimation was performed to confirm the structure of self-regulated climate scale. The values of fitness indicators show that the model benefits from good fitness. The outcome of confirmatory factor analysis indicates that Root Mean Square Error of Approximation (RMSEA) equal to 0.061, Comparative Fit Index (CFI) was 0.94, Goodness of Fit Index (GFI) was 0.91, Adjusted Goodness of Fit Index (AGFI) was 0.88, Normed Fit Index (NFI) was 0.88, Incremental Fit Index (IFI) was 0.94 , Tucker Lewis Index (TLI) was 0.93 and $\chi 2 / \mathrm{df}$ was 1.73 of which demonstrated a good fit with observed data. Factor loadings for the scale items were presented in Table 2. According to table 
2, coefficients of all items were above 0.30 .

In the fourth section, I compared gifted and public schools in self-regulated climate and its components. Since we have more than one dependent variable; one-way multivariate analysis of variance was run to determine the effect of school type (public or gifted) on self-regulated climate and its components. Before the analysis, we checked the MANOVA assumptions include normality; equality of variance, Absence of multivariate outliers, Linearity, Absence of multicollinearity and Equality of covariance matrices and no violation was observed. Three measures of self-regulated climate were assessed: collective faculty trust in students, collective student trust in teachers, and student-perceived academic emphasis. Data are expressed as the mean and the standard deviation in Table 3. The students of gifted school scored higher in three measures of self-regulated climate. The MANOVA results were presented in table 4.

The differences between the schools on the three variables was statistically significant, $\mathrm{F}(3,56)=83.99$, $\mathrm{p}<$ .0001 ; Wilks' $\Lambda=0.182$; partial $\eta 2=0.82$. Follow-up univariate ANOVAs results were presented in table 5 . Follow-up univariate ANOVAs showed that three variables scores (collective faculty trust in students, $\mathrm{F}(1,58)$ $=86.84, \mathrm{p}<.0001$; partial $\eta 2=0.60$ ), (collective student trust in teachers, $\mathrm{F}(1,58)=39.6, \mathrm{p}<.0001$; partial $\eta 2=0.40)$ and (student-perceived academic emphasis, $\mathrm{F}(1,58)=73.94, \mathrm{p}<.0001$; partial $\eta 2=0.56$ ) were statistically significantly different between the gifted and public schools.

Table 1. The correlation matrix and descriptive statistics (mean and standard deviation)

\begin{tabular}{|c|c|c|c|c|c|}
\hline Variable & Faculty trust in students & Student trust in teachers & academic emphasis & Mean & SD \\
\hline Faculty trust in students & 1 & & & 12.28 & 5.36 \\
\hline Student trust in teachers & $0.61^{* *}$ & 1 & & 11.38 & 4.61 \\
\hline Academic emphasis & $0.47^{* *}$ & $0.68^{* *}$ & 1 & 9.64 & 4.22 \\
\hline Self-regulated climate & $0.84^{* *}$ & $0.89^{* *}$ & $0.82^{* *}$ & 33.30 & 12.07 \\
\hline
\end{tabular}

${ }^{* *}$ Significance level: $0.01 *$ Significance level: $0.05, \mathrm{~N}=200$

Table 2. The confirmatory factor analysis on self-regulated climate items

\begin{tabular}{|c|c|c|c|}
\hline Factors & Faculty trust in students & Student trust in teachers & Academic emphasis \\
\hline$\%$ of Variance & 54 & 75 & 29 \\
\hline Items & \multicolumn{3}{|c|}{ Factor Loadings } \\
\hline 1 & 0.62 & & \\
\hline 2 & 0.66 & & \\
\hline 3 & 0.35 & & \\
\hline 4 & 0.53 & & \\
\hline 5 & 0.63 & & \\
\hline 6 & & 0.79 & \\
\hline 7 & & 0.79 & \\
\hline 8 & & 0.76 & \\
\hline 9 & & 0.77 & \\
\hline 10 & & 0.68 & \\
\hline 11 & & & 0.51 \\
\hline 12 & & & 0.77 \\
\hline 13 & & & 0.70 \\
\hline 14 & & & 0.71 \\
\hline 15 & & & 0.50 \\
\hline
\end{tabular}


Table 3. Mean and standard deviation of research variables

\begin{tabular}{|l|l|l|l|l|}
\hline Variable & School & Mean & Std. Deviation & N \\
\hline \multirow{4}{*}{ Faculty trust in students } & gifted & 16.30 & 1.84 & 30 \\
\cline { 2 - 5 } & public & 12.23 & 1.52 & 30 \\
\cline { 2 - 5 } & Total & 14.26 & 2.64 & 60 \\
\hline \multirow{4}{*}{ Student trust in teachers } & gifted & 15.13 & 1.77 & 30 \\
\cline { 2 - 5 } & public & 12.23 & 1.81 & 30 \\
\cline { 2 - 5 } & Total & 13.68 & 2.30 & 60 \\
\hline \multirow{3}{*}{ Academic emphasis } & gifted & 14.50 & 1.16 & 30 \\
\cline { 2 - 5 } & public & 11.83 & 1.23 & 30 \\
\cline { 2 - 4 } & Total & 13.16 & 1.79 & 60 \\
\hline
\end{tabular}

Table 4. Results of MANOVA three measures of self-regulated climate

\begin{tabular}{|c|c|c|c|c|c|c|c|}
\hline \multirow{4}{*}{ Effect } & Test & Value & F & DF Hypothesis & DF Error & Sig. & Partial Eta \\
\hline \multirow{4}{*}{ School } & Pillai's Trace & 0.81 & 83.99 & 3 & 56 & 0.001 & 0.82 \\
\cline { 2 - 9 } & Wilks' Lambda & 0.18 & 83.99 & 3 & 56 & 0.001 & 0.82 \\
\cline { 2 - 9 } & Hoteling's Trace & 4.49 & 83.99 & 3 & 56 & 0.001 & 0.82 \\
\cline { 2 - 9 } & Roy's Largest Root & 4.49 & 83.99 & 3 & 56 & 0.001 & 0.82 \\
\hline
\end{tabular}

Table 5. Results of Follow-up univariate ANOVAs

\begin{tabular}{|l|l|c|c|c|}
\hline Effect & Dependent variable & F & Sig. & Partial Eta \\
\hline \multirow{3}{*}{ School } & Faculty trust in students & 86.84 & 0.001 & 0.60 \\
\cline { 2 - 6 } & Student trust in teachers & 39.16 & 0.001 & 0.40 \\
\cline { 2 - 5 } & Academic emphasis & 73.94 & 0.001 & 0.56 \\
\hline
\end{tabular}

\section{Discussion}

The purpose of this study was to evaluate the psychometric properties of the self-regulated climate scale and to compare the public and gifted schools in self-regulated climate. Our results indicated that the self-regulatory climate scale has proper psychometric properties and the gifted schools benefit a high self-regulatory climate. In general, according to the results, the questionnaire is suitable for measuring the self-regulated climate. The evidence obtained from carrying out the confirmatory analysis revealed that the factor structure of the Persian version of the self-regulated scale is consistent with the original version. Also, the reliability coefficients for all factors and the total questionnaire were higher than 0.70 , which indicates good reliability.

The results are in line with the studies that examined the validity and reliability of this scale and related ones (Adams et al., 2015; Ford \& Ware, 2018; Hoy, Smith, \& Sweetland, 2002).

According to confirmatory analysis, the Faculty trust in students' factor explained approximately $54 \%$ of the self-regulatory climate variance. Faculty trust accelerates autonomy-supportive structures and activities. Low trust requires tight controls that rely on external factors to regulate behavior (Forsyth, Adams, \& Hoy, 2011). Adams et al. (2015) believed that student trust and academic emphasis somewhat depend on high faculty trust. Self-regulatory climate greatly depends on interactions and commitments between teachers and students. Faculty trust reflects the teacher's role in this interaction. Faculty trust facilitates students' engagement in academic activities and increases student's motivation.

According to the self-determination theory, teachers with high faculty trust use student-centered instructional 
approaches, engage students in learning through non-controlling language, persuade choice in the selection of tasks and projects, and allow for autonomous thinking (Black \& Deci, 2000; Hardre \& Reeve, 2003; Ryan \& Deci, 2016; Soenens \& Vansteenkiste, 2005).

Collective faculty trust in students is rooted autonomy support and related to shared perceptions and beliefs of the faculty in the school. Faculty interactions with students and their expectations for student performance shape the way learning is occurred. Autonomy-supportive structures are related to positive faculty perceptions and high expectations about student. Therefore, collective faculty trust in students is a translation of autonomy support at the school level. According to Forsyth, Adams, and Hoy (2011) Collective trust is "a stable group property rooted in the shared perceptions and affect about the trust worthiness of another group or individual that emerges over time out of multiple social exchanges within the group" (p. 22).

Autonomy support has a social nature and it can regulate student learning (Assor, Kaplan, \& Roth, 2002). Teachers and faculty school support student autonomy by stating the relevance of content and academic tasks, using flexible informational language to involve students in academic activities, allowing the selection of projects and assignments, and permitting for self-regulating thinking (Jang, Reeve, \& Deci, 2010). Collective faculty trust in students is promoted when teachers and schools support independent thinking, encourage students to complete meaningful and significant tasks, and use internal contingencies to motivate student behavior (Assor et al., 2002). The important outputs of autonomy-supportive school environments are internal regulation and higher academic performance (Niemiec \& Ryan, 2009). Teachers and faculty schools promote autonomy-supportive activities by encourage curiosity, and create interest by assisting learners believe they can control their own academic behaviors that lead to goal attainment.

Results also indicated that the student trust in teachers' factor explained about $75 \%$ of the self-regulatory climate variance. According to the related literature, this component is rooted in a relational environment (Reeve, Ryan, Deci, \& Jang, 2008). Relational support develops through the student-teacher interactions that produce strong student attachments to teachers and learning activities (Ryan \& Deci, 2016).

There is a relational support when there is collective student trust in teachers. High student trust shows a relational climate where students feel attached to teachers and motivated by academic activities. Attachment theory views attachment to school as an expanded form of the concept of attachment (Barber \& Schluterman, 2008). Barber and Olsen (1997) believe that attachment to adult symbols at school is an extended form of early parenting relationship. Accordingly, the school can ideally provide opportunities for students to increase their initial positive attachments to adults or to repair and healing weak and injured attachments by linking to adult patterns at school.

The students trust in teachers motivates students to think purposive and consider school and academic activities as a tool to achieve goals. Adams et al. (2015) believe a climate of relational support exists when there is student trust in teachers. Student trust is an indicator of students' connection sense to teachers and facilitates the learning activities. Mitchell, Kensler, and Tschannen-Moran (2018) show that student trust in teachers related to student identification with school. Student identification with school, in turn, more highly associated with academic motivation.

The results of this study revealed the third components, namely student-perceived academic emphasis explained near the $30 \%$ of the self-regulatory climate variance. Along with the original study, the least amount of variance accounted by this component. According to Adams et al. (2015), the student-perceived academic 
emphasis is rooted in a climate of competence support. Goddard, Sweetland, and Hoy (2000) believe academic emphasis refers to a school climate where students perceive high academic expectations from teachers and peers and believe the collective effort of the school encourages students to achieve academic goals. High academic emphasis leads to high academic expectations, encouraging students to work hard in class, and celebrating academic excellence (Hoy, Tarter, \& Hoy, 2006). The social cognitive theory, as a theoretical framework, explains the development and effect of the academic emphasis on student achievement. According to this theory, in schools with high academic emphasis, due to agency, vicarious learning, and self-regulation, teachers, and students try harder to enhance academic achievement (Martin, 2004).

Also, our results indicated that gifted schools have a higher self-regulation climate than public schools. Our results are relatively consistent with results of other studies (Greene et al., 2008; Ruban \& Reis, 2006). These studies revealed that gifted students use more sophisticated self-regulatory strategies; but as we mentioned earlier, we didn't find studies to compare gifted and public schools in the context of self-regulation climate. One of the probable explanations for this difference is the different structure and school related policies in gifted schools in comparison to public schools in Iran. The gifted schools in Iran benefit from some advantages. Teachers of these schools usually are the well-experienced and they have high academic qualification levels such as master and Ph.D. degrees. They have a good and qualified interaction with students because of these advantages. Teachers who have a qualified interaction with students make a positive interaction with their students, create classroom more supportive to learning and meet students' developmental, emotional and educational needs. In this case, we can observe Faculty trust in students' component of self-regulated climate. Also, gifted schools are committed to having some policies that enhance academic learning. These schools are expected to have the best performance in high stakes tests and this expectancy is transferred to students. Hence, students perceived high academic emphasis and in turn, it encourages the self-regulated climate. In the case of student trust in teachers' components, we consider the relationship of this component with the first component. In other words, when teachers offer some interactions with their students, as a result, the students have a sense of trust in teachers too.

This study is the first one to evaluate psychometric properties of self-regulating climate questionnaire in Iran. Also, the current study is one of few studies that have conducted to compare gifted and public schools in self-regulated climate. Researchers and practitioners can study some correlations of this construct using this questionnaire. Our results revealed the gifted schools are higher than the public schools in self-regulated climate. It is recommended based on the current research results; some interventions should be designed to make a more self-regulated climate of public schools.

Along with the results, the present study has been accompanied by limitations, and the barriers related to gathering data tool and the study sample attributions are the most important of these limitations. First, this scale should be used as one of the information sources about self-regulated climate along with other measurements. Also, despite the good psychometric properties, this scale is still a self-report questionnaire, and hence its results should be interpreted with caution.

Finally, the sample is limited to the first-year high school male students, due to budget limitation, which can limit the generalization of the findings. Therefore, it is suggested that the psychometric properties of the questionnaire be examined in other samples of different ages and educational levels. Also, the validity of this questionnaire has been evaluated by the use of one method (factor analysis). Therefore, future studies could 
evaluate the validity of it with other methods of evaluating validity. The findings in the present study contribute to the growing literature on self-regulated climate and help to broaden this construct as well.

In general, the self-regulate-questionnaire is an appropriate tool that can be used in Iran due to the excellent validity and reliability and can be used in screening, research, and educational situations. This tool is one of the most useful tools available to study the various aspects of self-regulated climate and authors recommend it for use in future studies.

Funding: The author received no financial support for the research, authorship, and/or publication of this article.

Acknowledgements: I would like to thank all the participants for their cooperation in the project.

\section{References}

Adams, C. M., Forsyth, P. B., Dollarhide, E., Miskell, R., \& Ware, J. (2015). Self-regulatory climate: A social resource for student regulation and achievement. Teachers college record, 117(2), 1-28.

Adams, C. M., Ware, J. K., Miskell, R. C., \& Forsyth, P. B. (2016). Self-regulatory climate: A positive attribute of public schools. The Journal of Educational Research, 109(2), 169-180.

Assor, A., Kaplan, H., \& Roth, G. (2002). Choice is good, but relevance is excellent: Autonomy $\square$ enhancing and suppressing teacher behaviours predicting students' engagement in schoolwork. British journal of educational psychology, 72(2), 261-278.

Azevedo, R., \& Cromley, J. G. (2004). Does training on self-regulated learning facilitate students' learning with hypermedia? Journal of educational psychology, 96(3), 523.

Barber, B. K., \& Olsen, J. A. (1997). Socialization in context: Connection, regulation, and autonomy in the family, school, and neighborhood, and with peers. Journal of adolescent research, 12(2), 287-315.

Barber, B. K., \& Schluterman, J. M. (2008). Connectedness in the lives of children and adolescents: A call for greater conceptual clarity. Journal of Adolescent Health, 43(3), 209-216.

Black, A. E., \& Deci, E. L. (2000). The effects of instructors' autonomy support and students' autonomous motivation on learning organic chemistry: A self-determination theory perspective. Science education, 84(6), 740-756.

Cohen, J., McCabe, L., Michelli, N. M., \& Pickeral, T. (2009). School climate: Research, policy, practice, and teacher education. Teachers college record, 111(1), 180-213.

Connor, C. M., Day, S. L., Phillips, B., Sparapani, N., Ingebrand, S. W., McLean, L., . . Kaschak, M. P. (2016). Reciprocal Effects of Self $\square$ Regulation, Semantic Knowledge, and Reading Comprehension in Early Elementary School. Child development, 87(6), 1813-1824.

Connor, C. M., Ponitz, C. C., Phillips, B. M., Travis, Q. M., Glasney, S., \& Morrison, F. J. (2010). First graders' literacy and self-regulation gains: The effect of individualizing student instruction. Journal of School Psychology, 48(5), 433-455.

Deci, E. L., \& Ryan, R. M. (2008). Self-determination theory: A macrotheory of human motivation, development, and health. Canadian psychology/Psychologie canadienne, 49(3), 182.

Ford, T. G., \& Ware, J. K. (2018). Teacher self-regulatory climate: Conceptualizing an indicator of leader support for teacher learning and development. Leadership and Policy in Schools, 17(1), 27-51. 
Forsyth, P., Adams, C., \& Hoy, W. (2011). Collective trust: Why schools can't improve without it. New York, NY: Teachers College Press.

Goddard, R. D., Sweetland, S. R., \& Hoy, W. K. (2000). Academic emphasis of urban elementary schools and student achievement in reading and mathematics: A multilevel analysis. Educational Administration Quarterly, 36(5), 683-702.

Greene, J. A., Moos, D. C., Azevedo, R., \& Winters, F. I. (2008). Exploring differences between gifted and grade-level students' use of self-regulatory learning processes with hypermedia. Computers \& Education, 50(3), 1069-1083.

Hardre, P. L., \& Reeve, J. (2003). A motivational model of rural students' intentions to persist in, versus drop out of, high school. Journal of educational psychology, 95(2), 347.

Hoy, W. K., Smith, P. A., \& Sweetland, S. R. (2002). The development of the organizational climate index for high schools: Its measure and relationship to faculty trust. The High School Journal, 86(2), 38-49.

Hoy, W. K., Tarter, C. J., \& Hoy, A. W. (2006). Academic optimism of schools: A force for student achievement. American educational research journal, 43(3), 425-446.

Jang, H., Reeve, J., \& Deci, E. L. (2010). Engaging students in learning activities: It is not autonomy support or structure but autonomy support and structure. Journal of educational psychology, 102(3), 588.

Martin, J. (2004). Self-regulated learning, social cognitive theory, and agency. Educational Psychologist, $39(2), 135-145$.

McCaslin, M. (2009). Co-regulation of student motivation and emergent identity. Educational Psychologist, 44(2), 137-146.

McClelland, M. M., \& Cameron, C. E. (2011). Self-regulation and academic achievement in elementary school children. New Directions for Child and Adolescent Development, 2011(133), 29-44.

McNeely, C. A., Nonnemaker, J. M., \& Blum, R. W. (2002). Promoting school connectedness: Evidence from the national longitudinal study of adolescent health. Journal of school health, 72(4), 138-146.

Mitchell, R. M., Kensler, L., \& Tschannen-Moran, M. (2018). Student trust in teachers and student perceptions of safety: positive predictors of student identification with school. International Journal of Leadership in Education, 21(2), 135-154.

Niemiec, C. P., \& Ryan, R. M. (2009a). Autonomy, competence, and relatedness in the classroom: Applying self-determination theory to educational practice. School Field, 7(2), 133-144.

Niemiec, C. P., \& Ryan, R. M. (2009b). Autonomy, competence, and relatedness in the classroom: Applying self-determination theory to educational practice. Theory and research in Education, 7(2), 133-144.

Paloş, R., Munteanu, A., Costea, I., \& Macsinga, I. (2011). Motivational and cognitive variables with impact on academic performance Preliminary study. Procedia-Social and Behavioral Sciences, 15, 138-142.

Pintrich, P. R., Smith, D. A., Garcia, T., \& McKeachie, W. J. (1993). Reliability and predictive validity of the Motivated Strategies for Learning Questionnaire (MSLQ). Educational and psychological measurement, 53(3), 801-813.

Reeve, J., Ryan, R., Deci, E. L., \& Jang, H. (2008). Understanding and promoting autonomous self-regulation: A self-determination theory perspective. Motivation and self-regulated learning: Theory, research, and applications, 223-244.

Ruban, L., \& Reis, S. M. (2006). Patterns of self-regulatory strategy use among low-achieving and high-achieving university students. Roeper Review, 28(3), 148-156. 
Ryan, R. M., \& Deci, E. L. (2016). Facilitating and hindering motivation, learning, and well-being in schools: Research and observations from self-determination theory. Handbook on motivation at schools, 96-119.

Sajjadimonazah, H., \& pirkhaefi, A. (2017). Effectiveness of Creativity Therapy Model on Improving Motivation and Students' Educational Performance. Journal of Research in School and Virtual Learning, 3(4), 39-48.

Soenens, B., \& Vansteenkiste, M. (2005). Antecedents and outcomes of self-determination in 3 life domains: The role of parents' and teachers' autonomy support. Journal of youth and adolescence, 34(6), 589-604.

Weinstein, C. E., Palmer, D., \& Schulte, A. C. (1987). Learning and study strategies inventory (LASSI). Clearwater, FL: H \& H Publishing.

Wibrowski, C. R., Matthews, W. K., \& Kitsantas, A. (2017). The role of a skills learning support program on first-generation college students' self-regulation, motivation, and academic achievement: A longitudinal study. Journal of College Student Retention: Research, Theory \& Practice, 19(3), 317-332.

Zee, M., \& de Bree, E. (2017). Students' self-regulation and achievement in basic reading and math skills: the role of student-teacher relationships in middle childhood. European Journal of Developmental Psychology, 14(3), 265-280.

Zimmerman, B. J. (2002). Becoming a self-regulated learner: An overview. Theory into practice, 41(2), 64-70.

Zimmerman, B. J., \& Pons, M. M. (1986). Development of a structured interview for assessing student use of self-regulated learning strategies. American educational research journal, 23(4), 614-628. 